\title{
Methods for Mitigating Growth of Laser-Initiated Surface Damage on DKDP Optics at $351 \mathrm{~nm}$
}

\begin{abstract}
L.W. Hrubesh, R.B. Brusasco, W. Grundler, M.A. Norton, E.E. Donohue, W.A. Molander, S.L. Thompson, S.R. Strodtbeck, P.K. Whitman, M.D. Shirk, P.J. Wegner, M.C. Nostrand, and A.K. Burnham
\end{abstract}

This article was submitted to the Boulder Damage Symposium XXXIV: Annual Symposium on Optical Materials for High Power U.S. Department of Energy Lasers, Boulder, Colorado, September 16-18, 2002

Lawrence Livermore National Laboratory

October 11, 2002 


\section{DISCLAIMER}

This document was prepared as an account of work sponsored by an agency of the United States Government. Neither the United States Government nor the University of California nor any of their employees, makes any warranty, express or implied, or assumes any legal liability or responsibility for the accuracy, completeness, or usefulness of any information, apparatus, product, or process disclosed, or represents that its use would not infringe privately owned rights. Reference herein to any specific commercial product, process, or service by trade name, trademark, manufacturer, or otherwise, does not necessarily constitute or imply its endorsement, recommendation, or favoring by the United States Government or the University of California. The views and opinions of authors expressed herein do not necessarily state or reflect those of the United States Government or the University of California, and shall not be used for advertising or product endorsement purposes.

This is a preprint of a paper intended for publication in a journal or proceedings. Since changes may be made before publication, this preprint is made available with the understanding that it will not be cited or reproduced without the permission of the author.

This report has been reproduced directly from the best available copy.

Available electronically at http://www.doc.gov/bridge

Available for a processing fee to U.S. Department of Energy

And its contractors in paper from

U.S. Department of Energy

Office of Scientific and Technical Information

P.O. Box 62

Oak Ridge, TN 37831-0062

Telephone: (865) 576-8401

Facsimile: (865) 576-5728

E-mail: reports@adonis.osti.gov

Available for the sale to the public from

U.S. Department of Commerce

National Technical Information Service

5285 Port Royal Road

Springfield, VA 22161

Telephone: (800) 553-6847

Facsimile: (703) 605-6900

E-mail: orders@ntis.fedworld.gov

Online ordering: http://www.ntis.gov/ordering.htm

\section{OR}

Lawrence Livermore National Laboratory

Technical Information Department's Digital Library

http://www.llnl.gov/tid/Library.html 


\title{
Methods for mitigating growth of laser-initiated surface damage on DKDP optics at. $351 n m$
}

\author{
Lawrence W. Hrubesh*, Raymond B. Brusasco, Walter Grundler, Mary A. Norton, \\ Eugene E. Donohue, William A. Molander, Samuel L. Thompson, Steven R. Strodtbeck, \\ Pamela K. Whitman, Michael D. Shirk, Paul J. Wegner, Michael C. Nostrand and Alan K. Burnham \\ University of California \\ Lawrence Livermore National Laboratory \\ P.O. Box 808, L-592 \\ Livermore, CA 94550
}

\begin{abstract}
We report an experimental investigation of mitigating surface damage growth at $351 \mathrm{~nm}$ for machine-finished DKDP optics. The objective was to determine which methods could be applied to pre-initiated or retrieved-from-service optics, in order to stop further damage growth for large aperture DKDP optics used in high-peak-power laser applications. The test results, and the evaluation thereof, are presented for several mitigation methods applied to DKDP surface damage. The mitigation methods tested were $\mathrm{CW}-\mathrm{CO}_{2}$ laser processing, aqueous wet-etching, short-pulse laser ablation, and micromachining. We found that micro-machining, using a single crystal diamond tool to completely remove the damage pit, produces the most consistent results to halt the growth of surface damage on DKDP. We obtained the successful mitigation of laser-initiated surface damage sites as large as $0.14 \mathrm{~mm}$ diameter, for up to 1000 shots at $351 \mathrm{~nm}$ and fluences in the range of 2 to $13 \mathrm{~J} / \mathrm{cm}^{2}, \sim 11 \mathrm{~ns}$ pulse length. Data obtained to-date indicates that micro-machining is the preferred method to process large-aperture optics.
\end{abstract}

Keywords: laser damage, DKDP, surface damage growth mitigation, $\mathrm{CO}_{2}$ laser processing, micro-machining

\section{INTRODUCTION}

Surface damage initiated on machine finished DKDP surfaces during high-peak-power irradiation at 351nm encompasses only a fraction of the clear aperture area. However, studies have shown that the damage can grow with the number of shots at $351 \mathrm{~nm}$ at laser fluences above $\sim 5 \mathrm{~J} / \mathrm{cm}^{2}, 11 \mathrm{~ns}$ pulse length [1,2]. A substantial increase in the useful lifetime of the optics can be achieved by stopping damage growth, thus mitigating obscuration caused by growing damage. Ideally this can be accomplished by eliminating the damage sites while they are small and returning the surface to its undamaged state. We explored several methods to mitigate the growth of UV-laser-induced damage on DKDP crystals. Other studies at this Laboratory have focused on elucidating the mechanisms for initiation [3] and growth [4] of surface damage on DKDP optics, whereas this effort seeks to identify and validate a leading method to successfully terminate the growth of such damage on DKDP optics.

Prior to testing for successful mitigation methods, it was necessary to determine how surface damage on DKDP actually grows at $351 \mathrm{~nm}$. Since there was little data available at $351 \mathrm{~nm}$ prior to this work, we performed experiments to establish the

*Correspondence: Email: hrubesh1@llnl.gov., Telephone: 925-423-1691, Fax: 925-422-5099. 
growth behavior of surface damage on DKDP. These experiments were done for both mechanically produced damage such as indents and scratches, and laser-produced damage. While these experiments did not provide sufficient data to establish the conditions for predictable surface damage growth, we determined that surface damage may grow in three distinct ways. Rapid, potentially catastrophic growth is rare, but it can be triggered when the fluence exceeds $8 \mathrm{~J} / \mathrm{cm}^{2}$, at both $3 \mathrm{~ns}$ and $11 \mathrm{~ns}$ pulse durations. Surface damage more commonly grows at fluences greater than $6 \mathrm{~J} / \mathrm{cm}^{2}$, by a process of 'fragmentation' within the existing site, usually including the ejection of particles. In some cases, the 'fragmentation' occurs only during a fluence change, then stops altogether when the fluence is stable. In other cases, growth by 'fragmentation' may be triggered after many shots at a fixed fluence. These unpredictable growth responses are shown graphically in Fig. 1 for six almost identical mechanical indent sites.

The following sections describe the experiments and results of damage growth tests for the four mitigation methods considered in this study; $\mathrm{CW}-\mathrm{CO}_{2}$ laser processing, aqueous wet-etching, short-pulse laser ablation, and micro-machining. The objective was to determine which methods could be applied to pre-initiated or retrieved-from-service optics, in order to stop further damage growth for large-aperture DKDP optics used in high-peak-power laser applications. A specific goal was to obtain sufficient data and information to enable the selection of a single approach for processing large-scale optics. The results show that micro-machining, using a small, high speed motor and a single-crystal diamond bit that completely removes the damage pit, consistently halts the growth of surface damage on DKDP. We have used this method to process surface damage sites on a small-scale DKDP optic to demonstrate feasibility for processing large-scale optics.

\section{EXPERIMENTAL}

In our experimental program, we tested the growth of mitigated mechanical and laser-initiated damage pits, as well as the intrinsic growth behavior of the mitigation pits themselves. It was necessary to determine that the pits formed by the mitigation methods on undamaged surfaces did not cause other damage or grow with repeated illumination. In fact, this was the case for some of methods that were tested.

The survey experiments used the same type of DKDP sample; diamond tool machine-finished DKDP, $50 \mathrm{~mm} \times 50 \mathrm{~mm} x$ $10 \mathrm{~mm}$ thick. The damage pits were arranged on the exit surface of these samples in an array of 9 spots spaced by $\sim 10 \mathrm{~mm}$. Mechanically produced indents or scratches of various sizes and depths were produced by a Nano-Instruments, Model XP nano-indenter. For the laser-initiated pits, to avoid inducing bulk damage within the DKDP, we used a tight focused beam to place an array of 9 nominally uniform, equally spaced damage pits on the exit surface of DKDP samples. Each laserinitiated damage site was produced by a single pulse from a frequency-tripled Nd:YAG laser at $355 \mathrm{~nm}$, with a $0.9 \mathrm{~mm}$ beam diameter, at an average fluence of $\sim 75 \mathrm{~J} / \mathrm{cm}^{2}$ and a pulse length $\sim 7.5 \mathrm{~ns}$. Each of the mitigation methods had distinctive surface pits, with different shapes and sizes, as shown in Fig.2. Later experiments to qualify the micromachining mitigation method, were done using $150 \mathrm{~mm} \times 150 \mathrm{~mm} \times 10 \mathrm{~mm}$ thick samples, which had naturally occurring, laser-initiated surface damage sites on them. The experiments were done at $351 \mathrm{~nm}$, at both $\sim 3 \mathrm{~ns}$ and $\sim 11 \mathrm{~ns}$ pulse lengths.

The growth tests of the survey samples were all carried out in a vacuum chamber operating in the range from $\sim 10^{-5}$ torr to 5torr, in the slab laser facility at LLNL [1]. The sites were tested for growth using the frequency-tripled Nd-glass laser output, producing a $4 \mathrm{~mm} \times 6 \mathrm{~mm}$ flat-top beam at $351 \mathrm{~nm}$, with $\sim 11 \mathrm{~ns}$ pulse width at $1-12 \mathrm{~J} / \mathrm{cm}^{2}$. The fluence is ramped to condition the crystal against bulk damage, in all cases. The damage sites are illuminated by the laser at a rate of $0.5 \mathrm{~Hz}$ and images produced by the transmitted laser light are recorded after each laser shot. Any visible change of the test site during laser illumination indicated an ineffective mitigation method. The qualification tests were done at $2.5-10$ torr of nitrogen gas. Some tests were done in the slab laser facility using the same laser as the survey tests and others were done in the Optical Science Lab (OSL) facility, using a frequency tripled Nd-glass laser, which produced a $3 \mathrm{~cm}$ diameter flattop beam at $351 \mathrm{~nm}$, with $\sim 3 \mathrm{~ns}$ pulse width at $1-8 \mathrm{~J} / \mathrm{cm}^{2}$. 


\section{CW-CO $\mathrm{C}_{2}$ LASER EXPERIMENTS AND RESULTS}

$\mathrm{CO}_{2}$ lasers have been used successfully to mitigate surface damage growth on fused silica at $351 \mathrm{~nm}$ [5] but we were not aware of any attempts to use $\mathrm{CO}_{2}$ laser heating to treat existing damage on DKDP. We explored using a $\mathrm{CO}_{2}$ laser for mitigating surface damage growth on DKDP. Experiments were done using a Parallax, Inc. $20 \mathrm{~W} \mathrm{CW}-\mathrm{CO}_{2}$ laser and an external reed-switch to give variable pulse duration. This laser was operated at less than $1 \mathrm{~W} C W$ with a focused Gaussian beam, a $1 / \mathrm{e}^{2}$ beam diameter of $-0.1 \mathrm{~mm}$, for $1-100 \mathrm{~ms}$ pulse duration. The laser beam locally melted and evaporated the DKDP, typically producing shallow, uneven pits with raised edges (see Fig.2a). The average pit depth $(\sim 4-15 \mu \mathrm{m})$ depended on both laser power and the defocus length.

The initial growth tests for the $\mathrm{CO}_{2}$ laser-produced pits were performed in the slab laser facility at $351 \mathrm{~nm}, \sim 11 \mathrm{~ns}$. The pits on both bare surface and indent damages changed only while the fluence was being ramped, but essentially no change was observed for hundreds of subsequent shots at a fixed fluence. However, in later tests carried out in OSL at 3ns pulse duration, the $\mathrm{CO}_{2}$ laser-produced pits continued 'fragmentation' damage at fixed fluence shots, after ramping. The typical mode of pit damage during the fluence ramp was by 'fragmentation' within the pit, including particle ejection.

We conclude that the $\mathrm{CO}_{2}$ laser treatment is not a viable mitigation method because 'fragmentation' and particle ejection were not inhibited. However, this approach is worthy of further investigation if the source of absorption at $351 \mathrm{~nm}$ by the modified DKDP is determined and eliminated.

\section{WATER-ETCHING EXPERIMENTS AND RESULTS}

We tested wet-etching as a potential mitigation method on DKDP. Since liquid water quickly dissolves DKDP crystals, it is possible to remove an existing damage on the crystal surface by applying a small droplet of water to the damage spot and then removing the solution before it dries. However, this is complicated because water droplets tend to spread due to surface tension, resulting in a much larger affected area than the original damage size. We have employed means to produce and deliver very small droplets to control the spread of liquids at the crystal surface and to remove dissolved material. One method was to deliver a small droplet of water through a capillary surrounded by a co-axial, evacuated tube. Two variations were used; one with and one without oil, which was employed to limit the spread of water on the crystal surface and to inhibit drying. Another method was to deliver a jet of moist gas to the crystal surface through a micro-jet. The moisture in the gas jet condenses on the crystal and etches it. This process can also be configured with a co-axial vacuum tube to enable solution removal. These methods are depicted in Figs. 3a,b,c and the pits that they produce on the crystal surface are shown in Figs. 2b,c,d.

The water etch pits were tested for stability at $351 \mathrm{~nm}, \sim 11 \mathrm{~ns}$, in the slab laser facility. All such pits on bare surfaces and on indents damaged by 'fragmentation' at fluences $>6 \mathrm{~J} / \mathrm{cm}^{2}$. They continued to 'fragment' with subsequent laser shots, but the damage did not propagate beyond the edges and it was generally confined to the area within the pit itself (see Fig. 4). The edges of the etched pits contain some re-crystallized DKDP and meta-phosphates, which may have enhanced absorption and contribute to the damage.

From these preliminary test results, we conclude that wet-etching is not a viable mitigation method for DKDP because 'fragmentation' and particle ejection were not inhibited. This method would be the most difficult to apply for treatment of large-scale optics because it involves handling liquids near the optics, necessitating special considerations to prevent permanent damage of the optic. 


\section{SHORT-PULSE LASER ABLATION EXPERIMENTS AND RESULTS}

In principle, surface damage pits on DKDP can be removed by ablating the affected material using an ultra-short pulse laser. We attempted to use femtosecond laser pulses for this purpose as a possible mitigation method. We employed a Tisapphire laser that produced $150 \mathrm{fs}$ pulses at $416 \mathrm{~nm}$ wavelength, focussed at the crystal surface. A single pulse caused ablation of the DKDP, forming a smooth, shallow pit with very little debris or collateral damage (see Fig. 2e). Such pits were generally stable when illuminated by $351 \mathrm{~nm}, \sim 11 \mathrm{~ns}$ laser pulses at fluences up to $12 \mathrm{~J} / \mathrm{cm}^{2}$. However, when the femtosecond laser pulses are applied to existing damage pits on DKDP, they grow rapidly instead of ablating. Although we chose to abandon this method based on the preliminary results, we believe that more work is likely to produce laser conditions that will remove damage pits on DKDP without growth. This method would be preferred due to the ease of applying the laser beam to treat multiple sites on a large optic.

\section{MICRO-MACHINING EXPERIMENTS AND RESULTS}

An option for mitigating surface damage growth is the complete removal of the damage pit by micro-machining. We used a small, high-speed $(65,000 \mathrm{RPM})$ turbine motor and tiny bits to make shallow cuts into the crystal surface. Pits on DKDP that are made using carbide and diamond bits are shown in Fig. $2 \mathrm{f}$ and $2 \mathrm{~g}$, respectively. Such pits were tested for stability in the same manner as the pits made by the other methods. We found that the pits or digs made on the DKDP surface were very stable when illuminated by laser pulses at $351 \mathrm{~nm}$. Unlike the other methods, the micro-machined pits survived as many as 1000 laser shots at $351 \mathrm{~nm}, \sim 11 \mathrm{~ns}$, at fluences as high as $12 \mathrm{~J} / \mathrm{cm}^{2}$, without damaging or major 'fragmenting'; a few ( 2 out of 28) sites showed minor 'fragmentation' damage after 600 shots. We also used the single-crystal diamond micro-machining to remove existing surface damage on DKDP, then tested the sites at $351 \mathrm{~nm}, \sim 11 \mathrm{~ns}$ for 550 shots at $12 \mathrm{~J} / \mathrm{cm}^{2}$, without damage. Additional tests were done in the OSL facility to qualify the single-crystal diamond micromachining mitigation method at $351 \mathrm{~nm}$, 3ns pulse length. No new damage was observed on 10 tested sites for 10 shots at $8 \mathrm{~J} / \mathrm{cm}^{2}$. An example of the successful mitigation of an existing surface damage on a DKDP sample is shown in Fig. 5.

\section{SUMMARY}

A summary of the test results for each of the methods is given in Table 1. None of the tested pits showed rapid, catastrophic growth behavior, although rapid growth of entrance surface damage was observed on some of the same samples. When unmitigated indents damaged, it was by 'fragmentation'. Most mitigated sites damaged by 'fragmentation' within or at the edge of the mitigation pit. The threshold for 'fragmentation' of pits is $-5 \mathrm{~J} / \mathrm{cm}^{2}$ and most changes occur during the conditioning ramp between $5-12 \mathrm{~J} / \mathrm{cm}^{2}$. Only minor changes occur within the pits at constant fluence. Machined pits are generally non-damaging but some machined with oil damaged by 'fragmentation', usually at a single location on the edge of the pit. Micro-machining is the only method that produces completely stable pits at all of the test conditions.

Successful mitigation of several natural, laser-initiated surface damages was demonstrated on $150 \mathrm{~mm} \times 150 \mathrm{~mm} \times$ $10 \mathrm{~mm}$ samples of machine-finished DKDP samples, at $12 \mathrm{~J} / \mathrm{cm}^{2}, \sim 11 \mathrm{~ns}$, as well as, at $8 \mathrm{~J} / \mathrm{cm}^{2}, \sim 3 \mathrm{~ns}$. 
Table 1. Tabulated results of stability tests for mitigation methods applied to bare surfaces and to indent damages on DKDP surfaces. The conditions in these tests were the following: $351 \mathrm{~nm}$ wavelength, $\sim 1 \mathrm{lns}$ pulse length; a conditioning ramp from $1-12 \mathrm{~J} / \mathrm{cm}^{2}$ in $~ 50$ shots at each site; an additional 550 shots at $12 \mathrm{~J} / \mathrm{cm}^{2}$ at each site; an additional 200 shots at $-14 \mathrm{~J} / \mathrm{cm}^{2}$ on some sites.

Mitigation method

$\mathrm{CO}_{2}$ laser on bare surface

$\mathrm{CO}_{2}$ laser on mechanical indent

Vac. assisted micro-fount. on bare surface

Vac. assisted micro-fount. on mechan. indent

Oil assisted micro-fount. on bare surface

Oil assisted micro-fount. on mechan. indent

Femto-sec laser on bare surface

Femto-sec laser on mechanical indent

Carbide drill bit on bare surface

Carbide drill bit on mechanical indent

Single-crystal diamond bit on bare surface Single-crystal diamond bit on mechan. indents Single-crystal diamond bit on laser damage
Observed response of the pit

'fragmentation' only during fluence ramp

'fragmentation only during fluence ramp

'fragmentation' mostly at edges of pit

'fragmentation' mostly at edges of pit

'fragmentation' mostly at edges of pit

'fragmentation' at indent and at edges of pit

'fragmentation' mainly during fluence ramp

'fragmentation' mainly during fluence ramp

no change

'fragmentation' only where indent was not

completely removed

no changes

no changes

no changes

\section{CONCLUSIONS}

Mitigation of surface damage growth on DKDP at $351 \mathrm{~nm}$ is necessary to prevent 'fragmentation' and particle generation even if rapid, catastrophic growth rarely occurs. Several of the mitigation methods that were tested exhibited some stability for high fluences at $351 \mathrm{~nm}$, however, only the micro-machined pits on DKDP are completely stable.

Site-by-site processing of laser damage on DKDP with micro-machining, using a high-speed drill with a singlecrystal diamond bit mounted on a micro-positioning stage (see Fig.6), is a feasible mitigation method to apply to large-scale DKDP optics. Based on the results of this study, this is the primary mitigation method recommended for DKDP optics used in high-peak-power applications at $351 \mathrm{~nm}$.

\section{ACKNOWLEDGEMENTS}

We wish to acknowledge the help of many LLNL associates who contributed to this effort. M. Runkel, who provided the results and interpretations from his earlier work on surface damage growth and mitigation experiments. Those who performed experiments; B. Hollingsworth, W. Sell, J. Vickers, and those who provided samples, analysis, interpretations and perspectives; E. Miller, J. Ferreira, W. Siekhaus, A. Rubenchik, M. Feit and F. Genin. This work was performed under the auspices of the U. S. Department of Energy by the University of California, Lawrence Livermore National Laboratory under Contract No. W-7405-Eng-48. 


\section{REFERENCES}

1. M.A. Norton, L.W. Hrubesh, Z. Wu, E. Donohue, M.D. Feit, M.R. Kozlowski, D. Milam, K.P. Neeb,W.A. Molander, A.M. Rubenchik, W.D. Sell, P. Wegner, "Growth of Laser Initiated Damage in Fused Silica at 351nm," Laser Science and Technology Program Annual Report - 2000, LLNL Report UCRL-ID142744-00 and UCRL-JC-13964 (2001).

2. A.K. Burnham, L. Hackel, P. Wegner, T. Parham, L. Hrubesh, B. Penetrante, P. Whitman, S. Demos, J. Menapace, M. Runkel, M. Fluss, M. Key, T. Biesiada, "Improving $351 \mathrm{~nm}$ damage performance of large-aperture fused silica and DKDP optics," Laser-Induced Damage in Optical Materials, 2001, SPIE Vol. 4679, 173-185 (2002).

3. S.G. Demos, M.R. Kozlowski, M.C. Staggs, L.L. Chase, A.K. Burnham, H.B. Radousky, "Mechanisms to explain damage growth in optical materials," Laser-Induced Damage I n Optical Materials-2000, SPIE Vol. 4347, 277-284 (2001).

4. A.M. Rubenchik and M. Feit, "Initiation, growth, and mitigation of UV damage in fused silica," Laser-Induced Damage in Optical Materials, 2001, SPIE Vol. 4679, 79-94 (2002).

5. R.M. Brusasco, B.M. Penetrante, J.A. Butler, L.W. Hrubesh, "Localized $\mathrm{CO}_{2}$-laser treatment for mitigation of $351 \mathrm{~nm}$ damage growth in fused silica," in Laser-Induced Damage In Optical Materials:2001,SPIE Vol. 4679, 40-47 (2002). 


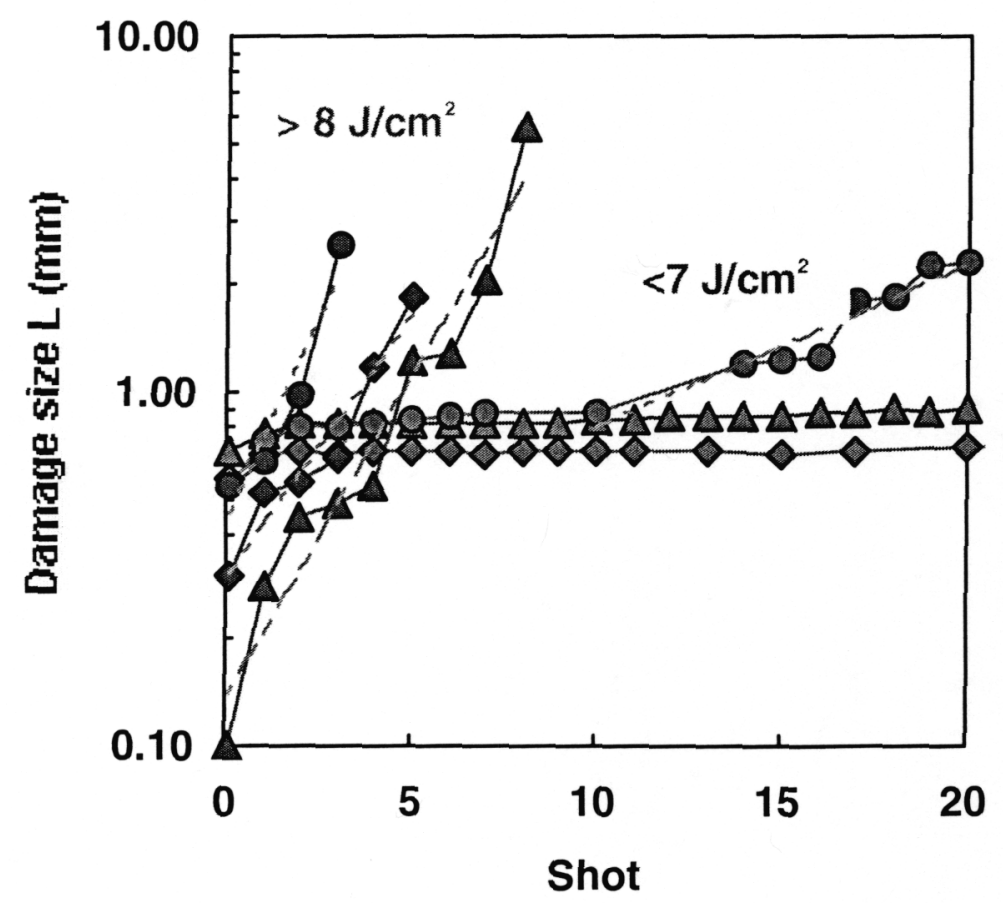

Figure 1. The growth rate of mechanical indent damage on DKDP at $351 \mathrm{~nm}, \sim 11 \mathrm{~ns}$, is not predictable. The graph shows growth responses for 6 nearly identical indent pits on DKDP. Rapid growth is rare but it is sometimes triggered at fluences $>8 \mathrm{~J} / \mathrm{cm}^{2}$. More commonly, 'fragmentation' occurs during the first few shots at fluences $>7 \mathrm{~J} / \mathrm{cm}^{2}$, then there is essentially no change for many following shots at constant fluence. Occasionally, slow 'fragmentation' growth may restart after a number of shots. 


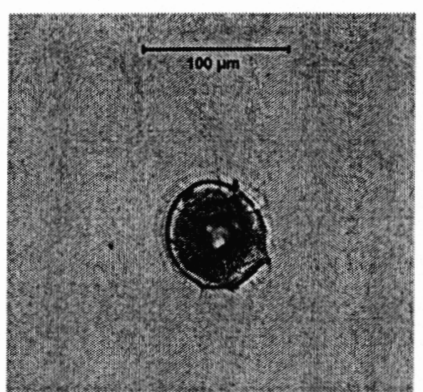

a) After 5 millisecond, $0.23 \mathrm{~W} \mathrm{CO} 2$ laser pulse

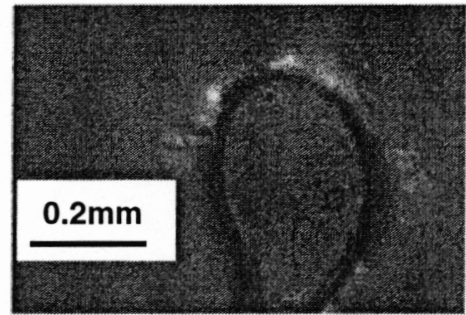

e) After a single $150 \mathrm{fs}$ laser pulse

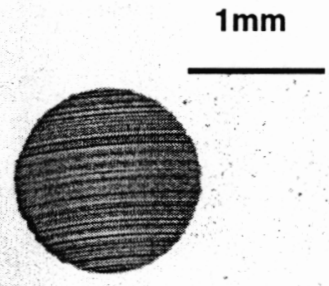

f) After micro-machining with a carbide bit

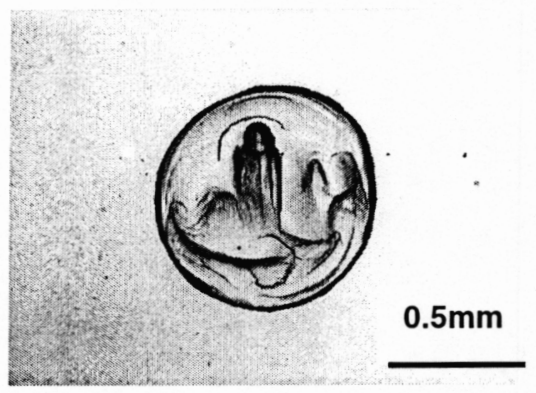

b) After dissolution by water and evaporation

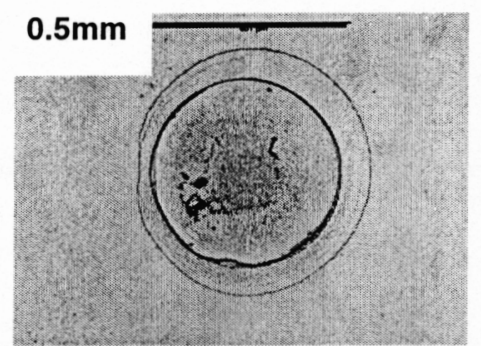

c) After dissolution by water/oil and evaporation

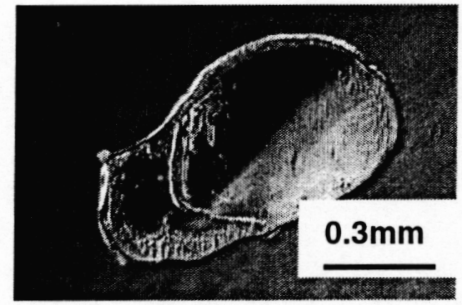

d) After dissolution by water from vapor jet

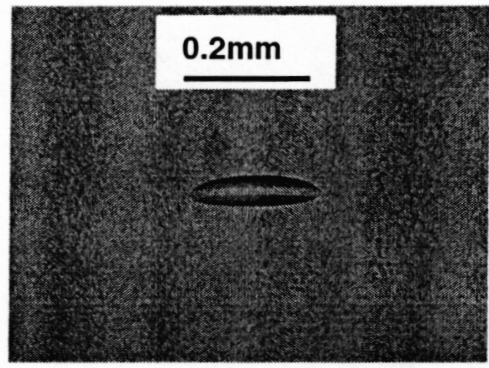

g) After micro-machining with a single-crystal diamond bit

Figure 2. Images of pits produced on DKDP surfaces by the mitigation methods that were tested in this study. 


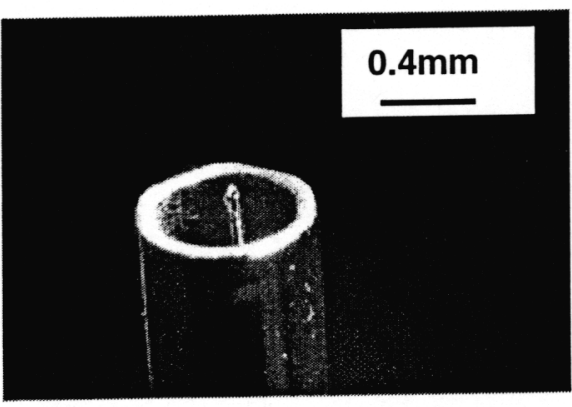

a) Vacuum-assisted micro-fountain

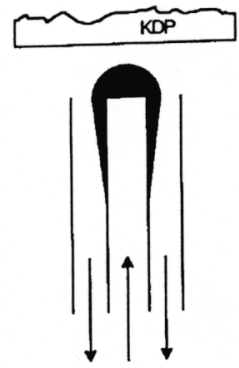

Approach surface with ovnamic water jet
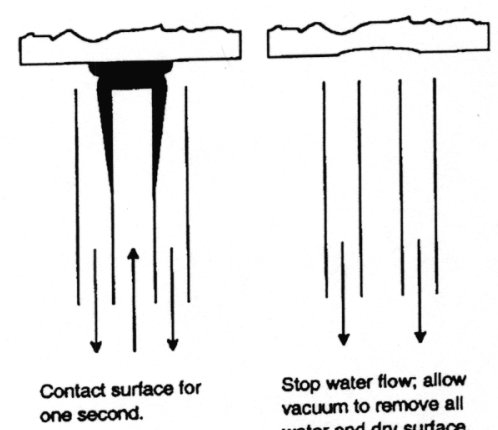

Stop water flow, allow vacuum to remove all water and dry surface.
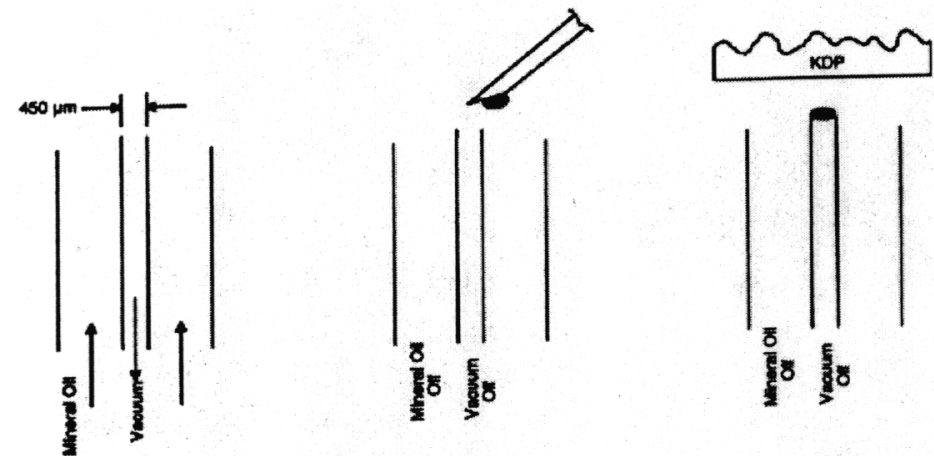

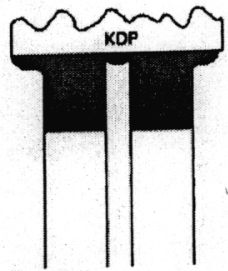

苗

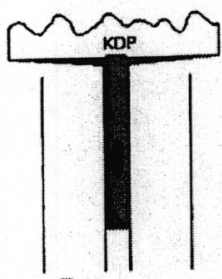

$\operatorname{lig}^{8}$

b) Oil-assisted micro-fountain

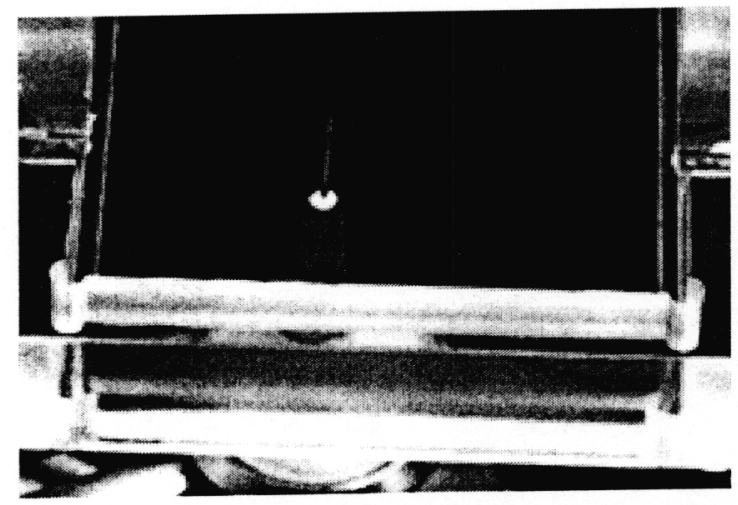

c) Water vapor jet

Figure 3. Three processes that were used to apply small amounts of water to the DKDP surface for wet-etching; a) vacuumassisted micro-fountain, b) oil-assisted micro-fountain, and c) water vapor jet. 

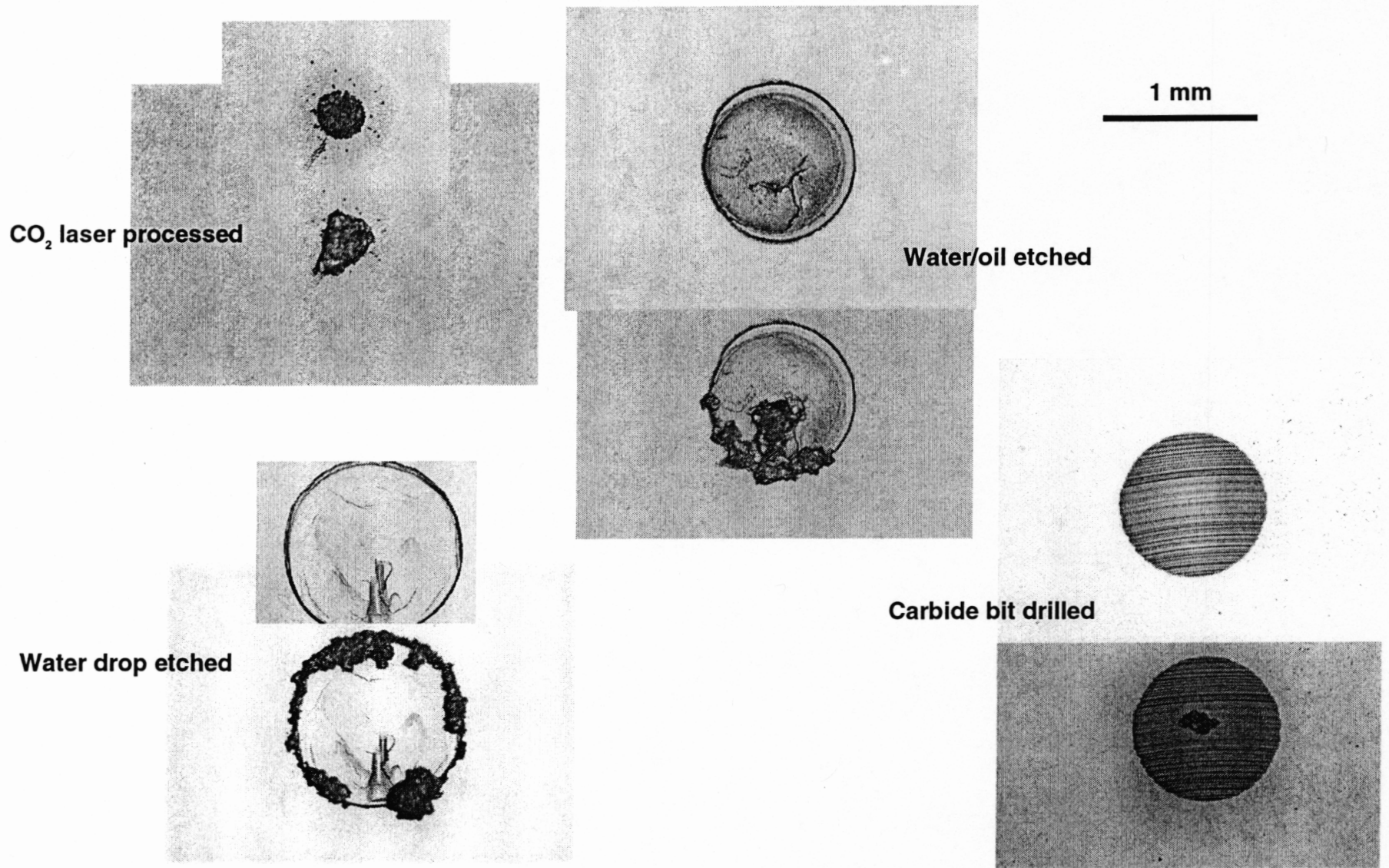

Figure 4. Before vs. after examples of 'fragmentation' damage that typically occurs during testing of mitigation pits at $351 \mathrm{~nm}$, $\sim 11 \mathrm{~ns},>6 \mathrm{~J} / \mathrm{cm}^{2}$. 
Damage grown from a mechanical indent after 600 shotsof $351 \mathrm{~nm} @ 12 \mathrm{~J} / \mathrm{cm}^{2}, 11 \mathrm{~ns}$.

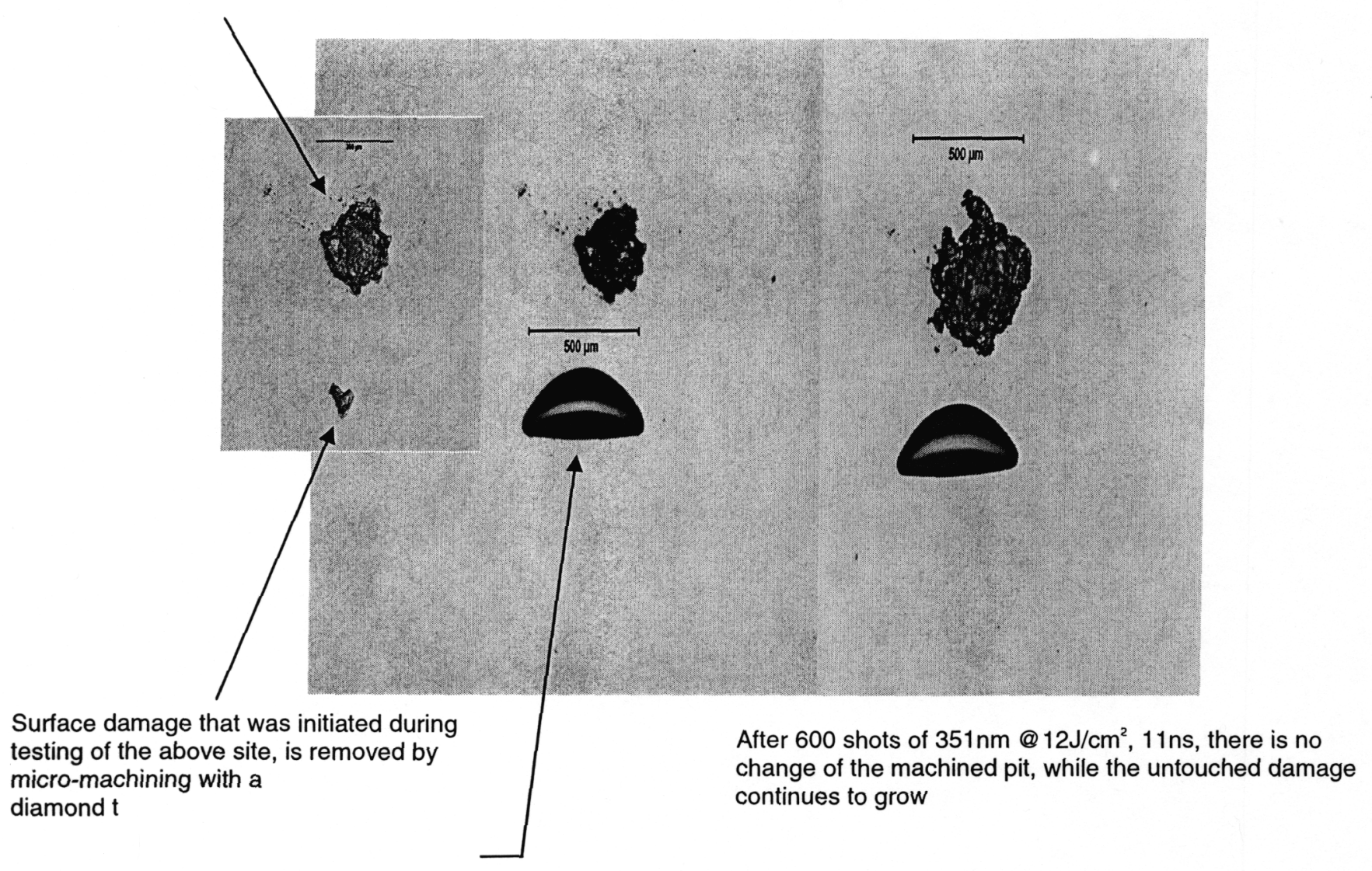

Figure 5. An example of the successful mitigation of a growing, laser-initiated surface damage on DKDP. 


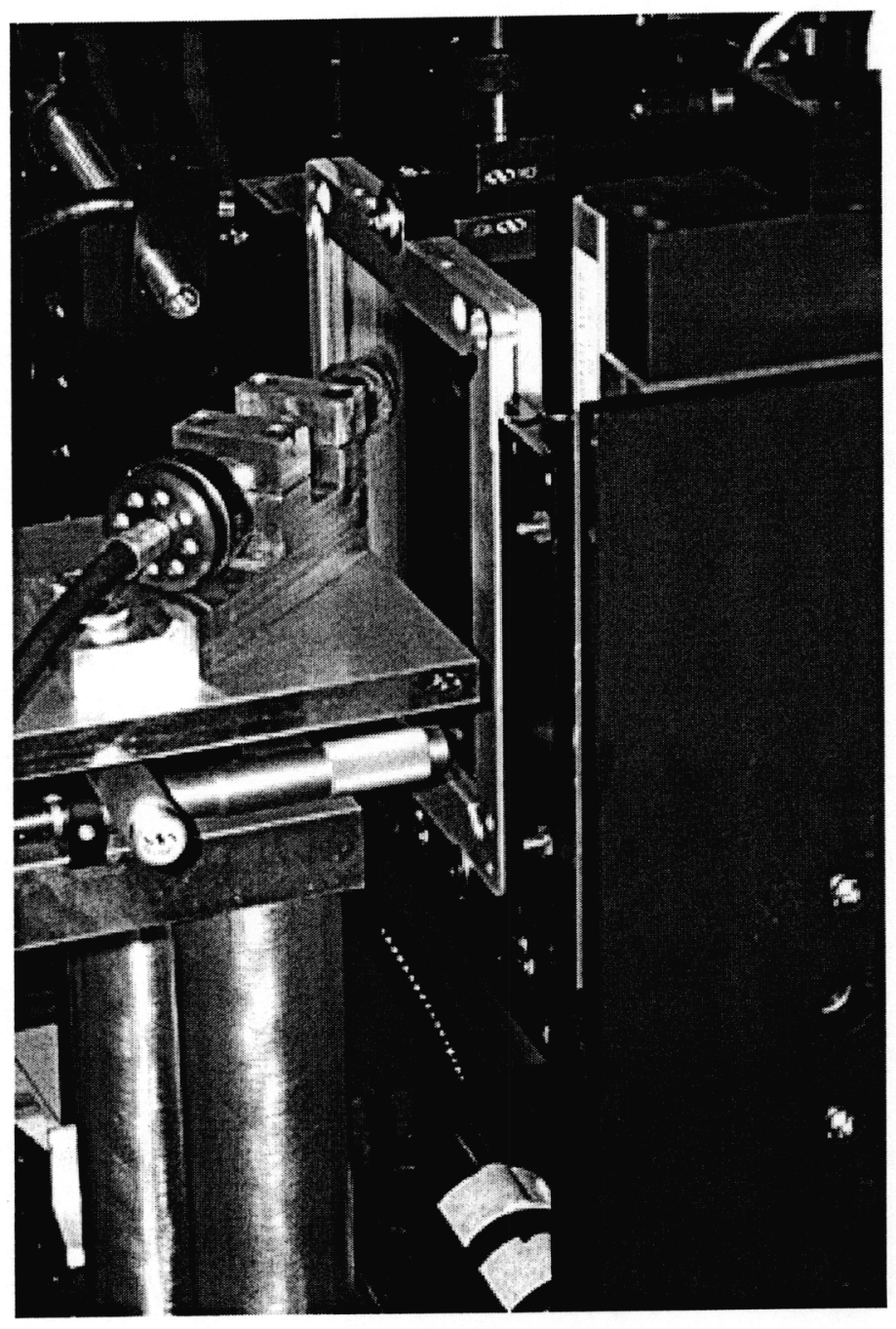

Figure 6. A photo showing a set-up for spot-to-spot processing of surface damages on small-scale DKDP crystals. The mitigation is accomplished by precision positioning of the optic on an $x-y$ stage, and precision positioning of the tool in the z-direction to control the depth of cut. 